\title{
Treatment related deaths during induction and in first remission in acute lymphoblastic leukaemia: MRC UKALL X
}

K Wheeler, J M Chessells, C C Bailey, S M Richards on behalf of the Medical Research Council Working Party on Childhood Leukaemia ${ }^{\star}$

\begin{abstract}
The benefits of achieving a long term event free survival of $60-70 \%$ by using increasingly intense treatment regimens must be weighed against the increased risk of treatment toxicity. From 1985 to 1990, 1612 children with childhood acute lymphoblastic leukaemia (ALL) in the UK were treated on MRC UKALL $X$ with intensive induction therapy, central nervous system directed therapy (cranial irradiation and intrathecal methotrexate), and continuing treatment for two years. There was a randomisation to receive blocks of additional intensification treatment at five weeks, 20 weeks, not at all, or both. The five year disease free survival was $71 \%$ for children randomised to two blocks of intensification, a 14\% improvement on children randomised to no intensification treatment.
\end{abstract}

Treatment related mortality in this national multicentre study has been analysed for induction and first remission (including those after intensification treatment). There were 38 induction deaths, $2 \cdot 3 \%$ and 53 deaths in first remission, $3 \cdot 3 \%$ (including those from a second malignancy). Thirty one $(84 \%)$ of the induction deaths followed an infection: bacterial in 22 and fungal in nine. Thirty seven infective remission deaths occurred: bacterial in 11 , viral in 16 , fungal in seven, and three caused by Pneumocystis carinii pneumonia. Ten of these deaths followed a block of intensification treatment. The majority of noninfective remission deaths followed the development of a second tumour.

Risk analysis for an induction death showed girls and children with Down's syndrome to be at greater risk. For deaths in first remission analysis showed an

${ }^{\star}$ Members of the working party during MRC UKALL $X$ were: O B Eden (chairman), C C Bailey, P R H Barbor, A Barrett, C Barton, V Broadbent, J M Chessells, S I Dempsey,

J Durrant, B Gibson, R Gray, I Hann, F G H Hill,

J Kernahan, J S Lilleyman, J R Mann, J Martin, T J McElwain (past chairman), S T Meller, P H Morris Jones, A Oakhill, J Peto, $M$ Radford, J K H Rees, S M Richards, R F Stevens, G P Summerfield, and E Thompson. increased risk for bone marrow transplant (BMT) patients and children with Down's syndrome. There was no effect of age and leucocyte count for either group. Most significantly when BMT patients were excluded from the analysis, intensification treatment did not increase the risk of remission death.

(Arch Dis Child 1996; 74: 101-107)

Keywords: acute lymphoblastic leukaemia, induction death, first remission death.

The long term event free survival for children with acute lymphoblastic leukaemia (ALL) is now of the order of $60-70 \%^{1}$ and the majority of these children are cured. These results have been achieved by increasing the intensity of chemotherapy but these benefits must be weighed against the increased risk of both short and long term toxicity.

Despite major advances in terms of new antibiotic regimens, supportive treatment, and indwelling central lines, some patients continue to succumb to these treatment related toxic effects, in particular to infections. The recently completed and reported MRC trial UKALL $\mathrm{X}^{2}$ offered an opportunity for examination of the factors influencing toxicity in a large cohort of patients. Since further intensifications of treatment are almost inevitable we hoped by this study to draw conclusions about toxicity which might help in future protocols.

\section{Patients and methods}

The patients comprised all the 1612 children who were entered in the MRC UKALL X trial. This trial accrued over $90 \%$ of children in the UK diagnosed with ALL up to the age of 15, from January 1985 to September 1990. The basic treatment scheme is shown in the figure. All received induction with four drugs: daunorubicin, vincristine, oral prednisolone, and subcutaneous asparaginase given over four weeks. A bone marrow aspirate was performed on completion of four weeks' induction treatment to assess remission status. Patients were randomised to receive an early block of intensification treatment at five weeks or a late block of 
intensification at 20 weeks, both, or neither. Exceptions were patients with central nervous system disease at diagnosis, an initial leucocyte count of $>100 \times 10^{9} /$, and, until April 1988, good risk girls (aged 2-9 years with an initial leucocyte count of $<20 \times 10^{9} / 1$ ). The composition of these blocks was identical (figure), consisting of a five day course of cytarabine etoposide and thioguanine with two doses of daunorubicin. Recovery of the blood count after this block normally occurred within three weeks. The details and toxicity of these treatment blocks have been described elsewhere. ${ }^{3}$ Maintenance treatment consisting of daily mercaptopurine, weekly oral methotrexate, and monthly vincristine with prednisolone was given for two years after remission had been achieved. The protocol contained clear instructions for the management of febrile neutropenia.

In the UKALL $X$ protocol central nervous system directed treatment was given to all children and consisted of intrathecal methotrexate in dosages based on age: three doses during induction, three doses during cranial irradiation, and one dose with each intensification block (if any) with cranial irradiation 1800 cGy in 10 fractions over two weeks in the second or third month depending on the treatment allocation. Young children had their cranial irradiation deferred until they were over 2 years of age. Prophylactic co-trimoxazole (trimethoprim, $160 \mathrm{mg} / \mathrm{m}^{2} /$ day, and sulphamethoxazole, $800 \mathrm{mg} / \mathrm{m}^{2} /$ day) was given by mouth for three days a week.

Patients with a leucocyte count at diagnosis of $>100 \times 10^{9} / 1$ were not randomised and because of their anticipated bad prognosis were electively treated with an early and late intensification block and $2400 \mathrm{cGy}$ of cranial irradiation, unless they had a histocompatible sibling donor when they were eligible for cyclophosphamide, total body irradiation, and bone marrow transplant (BMT) in first remission. ${ }^{4}$ Children with central nervous system disease at diagnosis (more than 5 cells $/ \mu 1$ cerebrospinal fluid recognisable as blast cells) were not randomised and were treated with an intensification block of chemotherapy in the fifth week, followed by craniospinal radiotherapy (2400 cGy to the cranium and 1200 cGy to the spine). In the early years of the trial the other group of non-randomised patients, good risk girls (see above) were allocated to no intensification treatment because of initial concern about the toxicity of the intensification. After April 1988 these girls were randomised.

The patients were followed up until 31 October 1994 so that all patients had been off treatment for at least one year. The maximum follow up of survivors was nine years and the minimum three years (median six years). All patients who died during induction or in first remission were analysed in this study. Statistical analysis was performed by the stratified log rank method to examine possible prognostic factors influencing the risk of death during induction and in first remission. ${ }^{5}$

\section{Results}

A total of 1612 children aged up to 15 years entered the UKALL $\mathrm{X}$ study and started induction treatment. There were 38 deaths that related to induction treatment alone. Thirty seven occurred in the first four weeks and none of these patients achieved remission. The one other patient who had only received induction treatment died on day 35 in remission. There were 26 patients who were not in remission at four weeks; seven of these were excluded from this analysis (three never achieved remission and four were treated with alternative protocols). One thousand five hundred and sixty seven children completed induction treatment and started maintenance treatment. Four hundred and seventy nine children did not receive any intensification block of chemotherapy, 283 randomised and 196 non-randomised (all these 196 were 'low risk' girls who were electively given no intensification blocks until April 1988). Three hundred and six received a block in the fifth week of treatment (early block), 283 randomised and 23 non-randomised (central nervous system disease at

Bone marrow
Intrathecal methotrexate
Cranial radiotherapy (18 Gy)
Asparaginase $6000\left(\mathrm{U} / \mathrm{m}^{2} \mathrm{sc}\right)$
Vincristine $\left(1.5 \mathrm{mg} / \mathrm{m}^{2} \mathrm{iv}\right)$
Daunorubicin $\left(45 \mathrm{mg} / \mathrm{m}^{2} \mathrm{iv}\right)$
Prednisolone $\left(40 \mathrm{mg} / \mathrm{m}^{2} \mathrm{po}\right)$
Etoposide $\left(100 \mathrm{mg} / \mathrm{m}^{2} \mathrm{iv}\right)$
Cytarabine
(100 $\mathrm{mg} / \mathrm{m}^{2}$ iv $\left.12 \mathrm{hourly}\right)$
Thioguanine $\left(80 \mathrm{mg} / \mathrm{m}^{2} \mathrm{po}\right)$
Mercaptopurine $\left(75 \mathrm{mg} / \mathrm{m}^{2} \mathrm{po}\right)$

Methotrexate $\left(20 \mathrm{mg} / \mathrm{m}^{2} \mathrm{po}\right)$

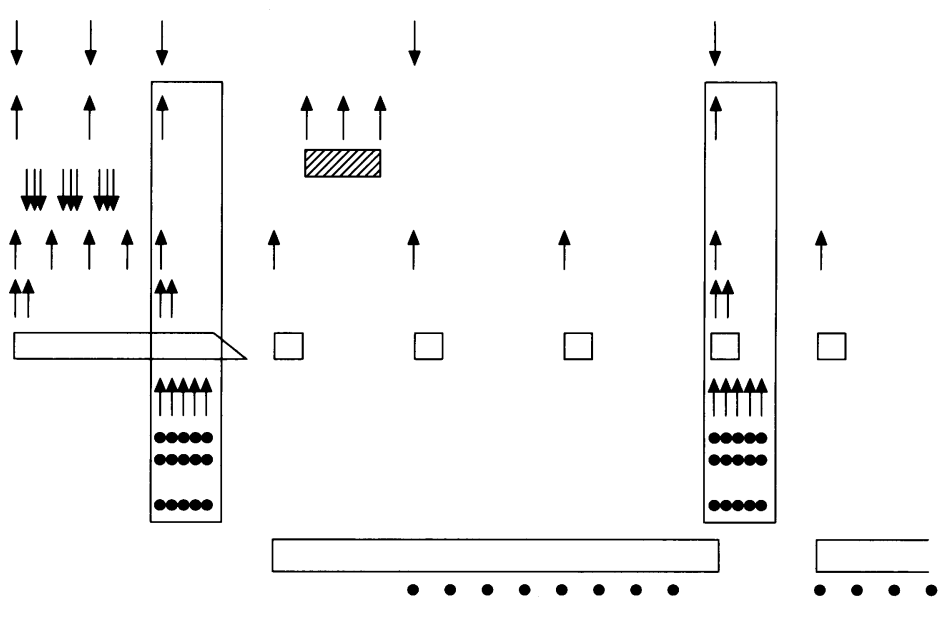

Week $\quad 1 \quad 2 \quad 3 \quad 4 \quad 5 \quad 6 \quad 7 \quad 8 \quad 91011121314151617181920212223242526$ 
Table 1 Details of deaths in MRC UKALL X

\begin{tabular}{|c|c|c|c|c|c|c|c|}
\hline \multirow[b]{3}{*}{ Treatment stage } & \multirow[b]{3}{*}{$\begin{array}{l}\text { No of } \\
\text { children }\end{array}$} & \multicolumn{6}{|l|}{ Deaths } \\
\hline & & \multirow[b]{2}{*}{$\begin{array}{l}\text { Non- } \\
\text { infective }\end{array}$} & \multicolumn{4}{|l|}{ Infective } & \multirow[b]{2}{*}{ Total } \\
\hline & & & Bacterial & Viral & Fungal & $\begin{array}{l}\text { P carinii } \\
\text { pneumonia }\end{array}$ & \\
\hline $\begin{array}{l}\text { Induction } \\
\text { Continuing treatment }\end{array}$ & $\begin{array}{l}1612 \\
1567\end{array}$ & 7 & 22 & 0 & 9 & 0 & 38 \\
\hline $\begin{array}{l}\text { Early block } \\
\text { Late block } \\
\text { BMT } \\
\text { Maintenance treatment } \\
\text { Off treatment }\end{array}$ & $\begin{array}{r}752 \\
729 \\
42\end{array}$ & $\begin{array}{l}0 \\
0 \\
2 \\
6 \\
8\end{array}$ & $\begin{array}{l}2 \\
3 \\
0 \\
6 \\
0\end{array}$ & $\begin{array}{r}0 \\
1 \\
2 \\
13 \\
0\end{array}$ & $\begin{array}{l}1 \\
3 \\
2 \\
1 \\
0\end{array}$ & $\begin{array}{l}0 \\
0 \\
2 \\
1 \\
0\end{array}$ & $\begin{array}{r}3 \\
7 \\
8 \\
27 \\
8\end{array}$ \\
\hline Total & & 23 & 33 & 16 & 16 & 3 & 91 \\
\hline
\end{tabular}

diagnosis). Two hundred and eighty three were randomised to a block in the 20th week of treatment (late block). Four hundred and forty six received both blocks, 289 randomised and 157 non-randomised (all 157 were high risk patients with a peripheral leucocyte count $>100 \times 10^{9} / 1$ at diagnosis). Fifty three patients had a BMT in first remission, 42 allogeneic and 11 autologous. Twenty nine children had central nervous system disease at diagnosis. The results are summarised in table 1 .

\section{INDUCTION DEATHS}

\section{Infective}

Twenty two of the 31 infective deaths were from a bacterial cause. Seventeen of these 22 occurred in the second and third week of induction treatment. The majority $(n=12)$ of these infections were due to a Gram negative organism. There were eight pseudomonal infections, three infections from Escherichia coli, and one infection caused by the anaerobic Gram negative organism Bacteroides fragilis. Two of these pseudomonal infections had presented with features typical of necrotising fasciitis and in another severe colitis had necessitated a laparotomy when a paracaecal abscess was found. There were seven Gram positive infections: a case each of pneumococcal septicaemia and pneumococcal meningitis, three cases of overwhelming Staphylococcus aureus infection (one in combination with an enterococcal septicaemia), and two cases of septicaemia with Corynebacterium spp. One of these latter had severe electrolyte imbalance and myocarditis, and the other a severe herpetic lesion of the cheek with localised necrosis and cellulitis, followed by systemic infection that failed to respond to appropriate medical and radical surgical treatment. Three children developed what was clinically felt to be overwhelming bacterial sepsis, but no organism was ever isolated. One of these was a child with Down's syndrome who had associated abdominal inflammation and necrosis of the caecum.

Nine of the induction deaths followed fungal septicaemia, of which six occurred in the fourth week of induction treatment. There were four cases each of candidiasis and aspergillosis and one case of mucormycosis that was resistant to amphotericin. One of the cases of aspergillosis was a girl who had achieved remission by day 28 but died on day 35 of a ruptured subclavian artery due to invasive aspergillus. Six of these nine children had received antifungal treatment, three for more than four days before death, but three had not received any antifungal treatment before death presumably because the diagnosis had not been suspected.

\section{Non-infective}

Three of the seven non-infective deaths resulted from metabolic problems, all occurring in children with a leucocyte count before treatment of $>100 \times 10^{9} /$. Three developed acute renal failure, two secondary to tumour lysis syndrome and one after leucostasis. Overwhelming haemorrhagic problems occurred in four children: one had a cerebral haemorrhage, two had pulmonary haemorrhages, and in the fourth patient (leucocyte count before treatment $\left.>400 \times 10^{9} / 1\right)$ catastrophic disseminated intravascular coagulation developed when treatment began.

The overall induction death rate/year is shown in table 2 . The number of fungal induction deaths/year remained constant but there were fewer bacterial and non-infective deaths in the second half of the study. The overall induction death rate was $2.4 \%$ and it can be seen that this rate fell over the study period.

\section{DEATHS IN FIRST REMISSION}

Of the 53 remission deaths analysed in this paper 37 were due to an infective cause (table 1) and 16 to a non-infective cause. There were inadequate data to establish a relationship between haemotopoietic toxicity and infective remission deaths.

\section{After intensification chemotherapy}

Ten of the 37 infective first remission deaths followed an intensification block of chemotherapy: three after the block given at five weeks and seven after the 20 week block. The cause of the three deaths that occurred after the early block were a fungal septicaemia, a Streptococcus mitis septicaemia, and a case of Gram negative septicaemia in a 4 month old child who had severe diarrhoea and electrolyte imbalance. Seven deaths followed the later intensification block. Three of these were due to fungal infections, three followed bacterial infections, and there was one viral death. Two of these seven deaths occurred in children with Down's syndrome (one fungal, one bacterial). Two of the three fungal deaths were very delayed deaths, of which one was in a child who had persistent

Table 2 Induction deaths/year of diagnosis

\begin{tabular}{|c|c|c|c|c|c|}
\hline \multirow{2}{*}{$\begin{array}{l}\text { Year of } \\
\text { diagnosis }\end{array}$} & \multirow[b]{2}{*}{ Total } & \multirow{2}{*}{$\begin{array}{l}\text { Total } \\
\text { No (\%) } \\
\text { deaths }\end{array}$} & \multicolumn{2}{|l|}{ Infective } & \multirow{2}{*}{$\begin{array}{l}\text { Non- } \\
\text { infective }\end{array}$} \\
\hline & & & Bacterial & Fungal & \\
\hline $\begin{array}{l}1985 \\
1986 \\
1987 \\
1988 \\
1989 \\
1990\end{array}$ & $\begin{array}{l}267 \\
277 \\
315 \\
304 \\
267 \\
182\end{array}$ & $\begin{array}{r}8(3 \cdot 0) \\
11(4 \cdot 0) \\
8(2 \cdot 5) \\
4(1 \cdot 3) \\
3(1 \cdot 1) \\
4(2 \cdot 2)\end{array}$ & $\begin{array}{l}4 \\
8 \\
5 \\
2 \\
1 \\
2\end{array}$ & $\begin{array}{l}1 \\
2 \\
2 \\
1 \\
2 \\
1\end{array}$ & $\begin{array}{l}3 \\
1 \\
1 \\
1 \\
0 \\
1\end{array}$ \\
\hline Total & 1612 & $38(2 \cdot 4)$ & 22 & 9 & 7 \\
\hline
\end{tabular}


Table 3 Induction and first remission infective deaths: types of organism

\begin{tabular}{lcc}
\hline Type of organism & Induction & Remission \\
\hline Bacterial (total) & 22 & 11 \\
Gram positive & 7 & 4 \\
Gram negative & 12 & 3 \\
'Septic' & 3 & 4 \\
Viral (total) & 0 & 16 \\
Measles & 0 & 5 \\
Herpes & 0 & 2 \\
Respiratory syncytial virus & 0 & 2 \\
Varicella zoster & 0 & 2 \\
Pneumonitis & 0 & 2 \\
Mumps & 0 & 1 \\
Cytomegalovirus & 0 & 1 \\
Encephalitis & 0 & 1 \\
Fungal (total) & 9 & 7 \\
Aspergillosis & 4 & 2 \\
Candidiasis & 4 & 3 \\
Mucormycosis & 1 & 0 \\
Unspecified & 0 & 2 \\
Pcarinii pneumonia & 0 & 3 \\
Total & 31 & 37 \\
\hline
\end{tabular}

hepatomegaly after the late block. In this child there was no response to amphotericin, encephalopathy developed, and the presumptive diagnosis was of progressive candida infection. The second late fungal death occurred after a long febrile illness. Candidiasis had been proved on liver biopsy but there had been no response to antifungal treatment. The third fungal death was due to overwhelming candidiasis and renal failure in a child with Down's syndrome. Of the three deaths that occurred from bacterial infection after the late intensification block, one was a case of overwhelming $E$ coli septicaemia in association with a large subarachnoid haemorrhage seven days after the start of the chemotherapy block, another was a child with severe diarrhoea and clinical pneumonia in whom an $\alpha$ haemolytic streptococcus was isolated, and the third death was in the child with Down's syndrome who had multiple problems after the late block with persistent diarrhoea, failure to thrive, intestinal cryptosporidiosis, and gastrointestinal haemorrhage. He was admitted from home, clinically bacteraemic, and severely dehydrated and resuscitation was unsuccessful. The only death due to a viral infection was in a child with interstitial pneumonia, presumed to be caused by cytomegalovirus infection, who died 13 days after the late block of treatment.

\section{Related to BMT}

Forty two first remission allogeneic BMTs were performed (34 for a high initial leucocyte count $>100 \times 10^{9} /$, eight for protocol violations). Of the eight deaths that occurred after a first remission allogeneic BMT six were due to infections: two fungal infections both in patients with significant graft-versus-host disease (GVHD), two cases of Pneumocystis carinii pneumonia that failed to respond to conventional treatment that occurred three months and 15 months after transplantation (the latter case had severe GVHD), and there was one case each of viral pneumonitis and disseminated varicella zoster virus. The two non-infective deaths were from severe GVHD and after a secondary tumour. No remission deaths occurred after the 11 autologous BMTs that were performed in first remission for various indications.

\section{During continuing treatment}

The remaining 21 deaths occurred during continuing maintenance treatment. Thirteen were due to viral infections; these included five cases of measles, all of whom developed measles pneumonitis, one combined with an encephalopathy. Two children died from herpes infections, one with disseminated herpes simplex infection and another had an encephalitis with an electroencephalogram compatible with herpetic disease. There were three cases of pneumonitis, two which were due to respiratory syncytial virus infection. One child died after overwhelming varicella zoster infection associated with a candidal septicaemia and there were two cases of encephalitis, one in a boy who had been exposed to mumps a few weeks previously. Six deaths followed bacterial infections. Two were cases of pneumococcal septicaemia and one an $E$ coli infection. Two children had overwhelming bacterial infection diagnosed clinically: one of these developed pneumonia at the end of treatment and at postmortem examination, liver changes were suggestive of $\alpha_{1}$-antitrypsin deficiency, but further studies did not confirm this and the cause of death was presumed to be bacterial. The sixth child had severe intestinal cryptosporidiosis and developed bilateral pulmonary consolidation unresponsive to conventional antibiotic treatment. Postmortem examination of the lungs showed diffuse alveolar damage and the presence of infected thrombi on the longline which suggested a possible diagnosis of septic pulmonary emboli. One child developed $P$ carinii pneumonia. Co-trimoxazole prophylaxis had been stopped six months previously because of a presumed co-trimoxazole related episode of erythema multiforme. She did not respond to treatment with high dose cotrimoxazole and pentamidine and died. Only one child died from disseminated aspergillosis during the continuing phase of treatment.

The infective remission deaths occurred during both the first and second year of chemotherapy. Bacterial deaths occurred with similar frequency in both years of treatment despite no blocks of intensification in year 2 . There were deaths from viral infections throughout the complete treatment period, none of them after an intensification block. In comparison four of the five deaths due to fungal infections occurred after a block.

The spectrum of infective agents causing death was different for induction compared with remission deaths (table 3 ). Gram negative septicaemia was a relatively common cause of death during induction whereas a viral cause of death only occurred in remission. Fungal infections occurred during induction and first remission.

\section{Other deaths}

Thirteen of the 16 non-infective deaths were due to a second malignancy. Five of these were diagnosed while the patient was receiving. maintenance treatment between 9-24 months after the original ALL diagnosis. There were two cases each of acute myeloid leukaemia and 
Table 4 Risk factors for death in induction

\begin{tabular}{lcccc}
\hline Factors & Total & Observed & Expected & p Value \\
\hline Gender & & & & \\
Male & 922 & 10 & 21.7 & $<0.005$ \\
Female & 690 & 28 & 16.3 & \\
Age (years) & & & & \\
$<2$ & 163 & 3 & 3.8 & NS \\
$2-9$ & 1212 & 27 & $28 \cdot 6$ & \\
$10+$ & 237 & 8 & $5 \cdot 6$ & \\
Leucocyte count $\left(\times 10^{9} / 1\right)$ & & & \\
$<10$ & 756 & 15 & $17 \cdot 8$ & \\
$10-19$ & 252 & 3 & 5.9 & \\
$20-49$ & 262 & 10 & $6 \cdot 2$ & \\
$50-99$ & 130 & 3 & 3.1 & \\
$100+$ & 212 & 7 & 5.0 & \\
Down's syndrome & 15 & 2 & 0.3 & $0.05^{\star}$ \\
Yes & 1576 & 35 & 36.7 & \\
No & 1576 & & \\
\hline
\end{tabular}

${ }^{\star}$ Fisher's exact test.

B-cell lymphoma, and laboratory studies confirmed all these to be second malignant neoplasms rather than relapses of an original acute mixed lineage leukaemia. There was one unusual case of possible malignant histiocytosis. The eight secondary tumours diagnosed after the completion of maintenance treatment (at 32-84 months) were four central nervous system tumours, one $T$ cell lymphoma, two cases of acute myeloid leukaemia (all proved to be second malignant neoplasms), and another case of Philadelphia positive acute myeloid leukaemia. At original diagnosis, this last case did not have a convincing Philadelphia chromosome but DNA studies showed a minor breakpoint cluster rearrangement that was also present at relapse ${ }^{6}$ suggesting a recurrent Philadelphia positive stem cell leukaemia rather than a true second malignancy.

Of the three non-infective deaths that were not due to a second malignancy the only case of fatal GVHD after a first remission BMT has been discussed, another child in whom there was no evidence of previous neurodegenerative disease developed a slowly progressive fatal cerebral degeneration after cranial radiation, and there was one death after a road traffic accident.

RISK FACTORS FOR DEATHS DURING INDUCTION AND FIRST REMISSION

Results of the analysis of the risk of an induction death in the 1612 children who started induction treatment are shown in table 4 . There was no effect of age or initial leucocyte count but girls were at greater risk, as were children with Down's syndrome. Table 5 shows the risk analysis for a first remission death in the 1567 patients who achieved remission. Age and sex had no effect, neither did diagnostic leucocyte as long as the BMT patients were excluded. Children with Down's syndrome were also at increased risk of a remission death, although the number of these children was very small. As expected the BMT patients had an increased risk of a remission death. If BMT patients were excluded there was no increased risk of remission death with intensification blocks of chemotherapy. There was a disproportionate number of deaths in induction among the non-randomised girls but this may have been because they were from the early part of the study when the overall rate of induction death was higher.

\section{Discussion}

This analysis of treatment related mortality in a large multicentre national study of children with ALL shows that despite protocol guidelines for supportive care, $2 \cdot 3 \%$ died during induction and a further $2.3 \%$ in first remission $(3.3 \%$ if second malignancy deaths are included). It is reassuring that despite the increased intensity of this protocol these toxicities are similar to those seen in German studies. ${ }^{7}$ However, they do compare unfavourably with recent results in the USA ${ }^{8}$ The extra intensification treatment in UKALL $X$ produced a significant improvement in disease free survival ${ }^{2}$ making an analysis of treatment related mortality such as this imperative for the full evaluation not only of this trial but also for future trials so that intensification treatment can be given effectively and safely. There are no detailed analyses of treatment related deaths from a large unselected cohort of children with ALL in a national protocol, making ours an important study. Other studies of treatment related deaths in ALL are smaller and have either involved a very different patient population ${ }^{9}$ or have been an analysis of deaths occurring in patients treated over many years at a single centre using a variety of treatment protocols. ${ }^{10}$

The remission rate was over $95 \%$ but 38 children $(2 \cdot 3 \%$ of the total) died during induction, 31 of these $(82 \%)$ as a result of infection. Despite the current use of intravenous catheters which has changed the spectrum of bacterial infections during chemotherapy, ${ }^{11}$ Gram positive infections accounted for only a small proportion of bacterial deaths, three being due to staphylococci. The majority of these deaths were due to Gram negative organisms, in particular, Pseudomonas sp and $E$ coli. Necrotising fasciitis from Pseudomonas sp developed in one child. This progressive

Table 5 Risk factors for death in first remission

\begin{tabular}{lcccl}
\hline Factors & Total & Observed & Expected & p Value \\
\hline Gender & & & & \\
Male & 908 & 34 & $31 \cdot 0$ & NS \\
Female & 659 & 19 & $22 \cdot 3$ & \\
Age (years) & & & & \\
$<2$ & 159 & 6 & $5 \cdot 4$ & NS \\
$2-9$ & 1181 & 35 & $40 \cdot 0$ & \\
$10+$ & 227 & 12 & $7 \cdot 7$ & \\
Leucocyte count & $(\times 109 / 1)$ & (excluding BMT patients) & \\
$<10$ & 738 & 18 & $21 \cdot 9$ & \\
$10-19$ & 245 & 8 & $7 \cdot 3$ & NS \\
$20-49$ & 246 & 6 & $7 \cdot 3$ & \\
$50-99$ & 125 & 7 & $3 \cdot 7$ & \\
$100+$ & 160 & 6 & $4 \cdot 7$ & \\
Down's syndrome & & & & \\
No & 1535 & 51 & $52 \cdot 5$ & $0 \cdot 07$ \\
Yes & 13 & 2 & $0 \cdot 4$ & \\
BMT & & & & \\
No & 1514 & 45 & $51 \cdot 2$ & $<0 \cdot 00005$ \\
Yes & 53 & 8 & $1 \cdot 8$ & \\
Intensification block (excluding BMT & patients) & \\
None & 283 & 6 & $8 \cdot 4$ & \\
Early & 283 & 6 & $8 \cdot 4$ & \\
Late & 283 & 12 & $8 \cdot 4$ & \\
Early+late & 289 & 9 & $8 \cdot 6$ & NS \\
Non-randomised & & & & \\
None & 196 & 5 & $5 \cdot 8$ & \\
Early & 23 & 1 & $0 \cdot 7$ & \\
Early+late & 157 & 6 & $4 \cdot 7$ & \\
& & & & \\
\hline
\end{tabular}


infection of the subcutaneous tissue must be recognised early and treated aggressively, both medically and surgically. ${ }^{12}$ There were nine deaths from fungal infections during induction. In the majority of cases a fungal cause for the child's illness had not been adequately considered, despite reports in the literature alerting physicians to the possibility of invasive fungal disease soon after the onset of induction chemotherapy. ${ }^{13}$ One third of these patients had received no antifungal treatment before death and another third had received inadequate treatment. Some physicians seem to be reluctant to consider the diagnosis of a fungal infection within the first few weeks of treatment as well as hesitant to treat an unresolved fever with antifungal medication. The paediatric antifungal drug of choice is amphotericin B. Sometimes there are concerns about prescribing it because it has significant renal toxic side effects. This problem may be relieved by the use of the more expensive but less toxic liposomal amphotericin.

Three of the seven non-infective induction deaths resulted from catastrophic metabolic complications when chemotherapy was started. Although these three patients had diagnostic leucocyte counts of $>100 \times 10^{9} /$, statistical analysis did not put children with a high initial leucocyte count at overall greater risk of induction death. Because the risk of severe metabolic disorder is to some extent predictable, these high risk patients all need expert supportive care which is best provided in an oncology centre with adequate paediatric intensive care back-up.

In this trial all the children received daunorubicin during induction so its contribution, if any, to the toxic death rate cannot be assessed. In UKALL VIII (the preceding MRC ALL trial) the children randomised to receive daunorubicin treatment had an increased chance of induction and remission deaths. This was counterbalanced by an increased relapse free survival which did not reach statistical significance. ${ }^{14}$ Because of this finding and increasing concern over accumulative cardiotoxic effects ${ }^{15}$ daunorubicin is being omitted from some induction regimens, for example the current ALL trial, MRC UKALL $\mathrm{XI}$, which may reduce toxic deaths. However, if long term disease free survival proves to be better with daunorubicin and induction and infective deaths can be controlled, as well as more information obtained on the optimal administration of anthracyclines (in respect of reducing damage to the myocardium), there may be a real value for daunorubicin in induction for a select group of patients. No child in UKALL X received more than $270 \mathrm{mg} / \mathrm{m}^{2}$ of daunorubicin and to date there have been no first remission deaths from an anthracycline induced cardiomyopathy.

The spectrum of infections causing first remission deaths was significantly different from that during induction, viral infections being most common. Measles was the commonest viral pathogen. Since 1990 the incidence of measles infection in the UK has fallen due to the currently very successful vaccination programme with measles and subsequently measles, mumps, and rubella vaccine ${ }^{16}$ and it had been anticipated that measles would become rare as a cause of death. However, because there was considerable concern in the UK that there would be an epidemic of measles in early 1995 the Department of Health launched a measles and rubella vaccination schedule for children of school age. If this epidemic is not curtailed by these measures there could again be a significant morbidity and mortality risk for immunocompromised children especially those on chemotherapy. Chickenpox deaths are now unusual due to the widespread and early use of zoster immune globulin and acyclovir. The one chickenpox death in this study was in a BMT patient who also had cutaneous GVHD. $P$ carinii pneumonia infection caused three deaths. One of these children had not been receiving co-trimoxazole treatment because of a presumed drug reaction to it and of the two $P$ carinii pneumonia deaths after BMT, one was over a year from transplantation and cotrimoxazole prophylaxis had been stopped. Darbyshire et al showed over a decade ago that the incidence of $P$ carinii pneumonia in childhood ALL can be successfully prevented when co-trimoxazole prophylaxis is taken. ${ }^{17}$ It is essential that there continues to be careful monitoring for the early signs of $P$ carinii pneumonia in those at risk patients who are not on co-trimoxazole prophylaxis and that prompt management is instituted. ${ }^{18}$

Long term disease free survival in UKALL $\mathrm{X}$ was significantly improved in the children who had received the extra blocks of intensive chemotherapy, the addition of two courses of intensification producing a $14 \%$ improvement in disease free survival. ${ }^{2}$ Although 10 deaths followed these blocks of treatment statistical analysis showed no evidence of intensification chemotherapy significantly predisposing to a remission death. The pattern of infective agents causing overwhelming infection after intensification is similar to that seen in the induction deaths, that is, bacterial and fungal with some gastrointestinal toxicity. Hepatosplenic candidiasis caused two of the deaths after intensification; this is now a recognised complication of chemotherapy. ${ }^{19}$ It always requires aggressive treatment, but unfortunately neither of these patients responded to antifungal drugs. All UKALL $\mathrm{X}$ patients received cranial irradiation and there is no evidence from other studies that infective complications of treatment are higher when cranial radiotherapy has been given. However, the small number of non-randomised early intensification patients, that is, those with central nervous system disease at diagnosis who received craniospinal irradiation, were not at increased risk of a remission death.

First remission BMT in selected high risk ALL patients reduces the risk of relapse, ${ }^{4}$ but it is associated with a significantly higher morbidity and mortality than treatment with chemotherapy alone. In this study eight patients died after a BMT, the majority $(n=6)$ from an infection. These deaths all occurred 
among the 34 patients with an initial leucocyte count of $>100 \times 10^{9} / 1$ who had an allogeneic BMT. In these patients the event free survival was improved (although non-significantly) compared with the similar group of patients receiving chemotherapy alone. ${ }^{4}$

This study highlighted three groups of patients particularly at risk of treatment related problems. During induction girls and children with Down's syndrome were at higher risk. The reason for female sex being a highly significant risk factor for an induction death is unclear and despite looking at a large number of risk factors we are unable to offer an obvious logical explanation. It has not been reported before and it may represent a chance occurrence. In first remission, risk factors were again children with Down's syndrome and patients receiving a first remission BMT. The predisposition of children with Down's syndrome on chemotherapy to acquiring infection has been well documented ${ }^{20}$ and is presumably due to underlying immunodeficiency. ${ }^{21} \mathrm{~A}$ review by the Paediatric Oncology Group found that in children with Down's syndrome there was a high incidence of serious toxicity associated with intensive chemotherapy treatment. This caused treatment interruption, but was responsible for only infrequent toxic deaths. ${ }^{22}$

There were 16 non-infective deaths in first remission. As expected, the majority $(n=13)$ were from second tumours, and there were a further five children who developed second tumours and are alive. Central nervous system tumours and acute myeloid leukaemia were the commonest second malignancies presumably related to cranial irradiation and epipodophyllotoxin treatment. The association between ALL and the development of these two secondary tumours is well documented 2324 and it is likely that more secondary tumours will develop as further time elapses from the completion of this study. The late effects after cranial irradiation are now well established, that is, neuropsychological sequelae, disturbances of growth, and the development of secondary tumours. In an attempt to avoid these, current ALL protocols are only using cranial radiotherapy in a few selected high risk patients which may result in a reduced incidence of secondary brain tumours.

This analysis of induction and first remission deaths demonstrates that improved disease free survival for patients treated on an intense treatment regimen is possible without increasing the risk of treatment related deaths. Future treatment for ALL is likely to become more intensive especially for the higher risk groups and a balance in treatment is needed to maximise long term disease free survival but minimise the toxic effects of treatment both short and long term. It is possible that some of these deaths could have been prevented with earlier, more judicious use of intensive care, appropriate antibiotic treatment and early antifungal treatment. The increased use of growth stimulating factors may help some of these patients with overwhelming infections during periods of neutropenia. Patients most at risk of treatment related problems are those with Down's syndrome and those undergoing BMT, but not those receiving blocks of intensification treatment. The diagnosis of second malignancies in these patients remains a major concern. Minor modifications to treatment protocols may alter the second malignancy incidence rate, but large multicentre epidemiological studies need to be undertaken to analyse which factors contribute to the development of such second malignancies.

1 Rivera GK, Pinker D, Simone JV, et al. Treatment of acute lymphoblastic leukimian $N$, et al. Treatment of acute lymphoblast $1289-95$.

2 Chessells JM, Bailey C, Richards SM. Intensification of treatment and survival in all children with lymphoblastic leukaemia - results of UK Medical Research Council trial UKALL X. Lancet 1995; 345: 143-8.

3 Pinkerton CR, Bowman A, Holtzel H, Chessells JM Intensive consolidation chemotherapy for acute lymphoblastic leukaemia (UKALL X pilot study). Arch Dis Child 1987; 62: 12-8.

4 Chessells JM, Bailey C, Wheeler K, Richards SM. Bone marrow transplantation for high-risk childhood lymphoblastic leukaemia in first remission: experience in MRC UKALL X. Lancet 1992; 340: 565-8.

5 Peto R, Pike MC, Armitage P, et al. Design and analysis of randomized clinical trials requiring prolonged observation of each patient. II. Analysis and examples. Br $f$ Cancer of each patient.

6 Jackson GH, Middleton P, Prince R. Philadelphia positive acute leukaemia with minor breakpoint cluster rearrangement may be a stem cell disease. Br $\mathcal{F}$ Haematol 1992; 81: 77-80.

7 Riehm H, Gadner H, Henze G, et al. Acute lymphoblastic leukaemia: treatment results in three BFM studies (1970-1981). Leukaemia research: advances in biology and treatment. New York: Elsevier Biomedical, 1983: 251-60

8 Tubergen DG, Gilchrist GS, O'Brien RT, et al. Improved outcome with delayed intensification for children with acute lymphoblastic leukaemia and intermediate presentacute lymphoblastic leukaemia and intermediate presenting fin Oncol 1993; 3: 527-37.

9 Chaudhry VP, Krishnamurthy L, Arya LS, et al. Causes of mortality in children with acute lymphoblastic leukaemia. Indian Pediatr 1991; 29: 709-13.

10 Atra A, Richards SM, Chessells JM. Remission death in acute lymphoblastic leukaemia: a changing pattern. Arch Dis Child 1993; 69: 550-4.

11 Viscoli C, Castagnola E, Rogers D. Infections in the compromised child. Ballieres Clin Haematol 1991; 41: 511-37.

12 Lou J, Low CH. Necrotizing fasciitis in leukaemic children. Ann Acad Med Singapore 1990; 19: 290-4.

13 Bömelburg T, Roos N, von Lengerke H-J, Ritter J. Invasive aspergillosis complicating induction chemotherapy of childhood leukaemia. Eur $f$ Pediatr 1992; 151: 485-7.

14 Eden OB, Lilleyman JS, Richards S, et al. Results of Medical Research Council childhood leukaemia trial UKALL VIII. Br 7 Haematol 1991; 78: 187-96.

15 Lipshultz SE, Colan SD, Gelber RD, et al. Late cardiac effects of doxorubicin therapy for acute lymphoblastic effects of doxorubicin therapy for acute lymphoblastic
leukaemia in childhood. $N$ Engl $\mathcal{f}$ Med 1991; 324: leukaem

16 Miller E, Nokes DJ, Anderson RM. Measles, mumps, and rubella vaccination. $B M F$ 1992; 304: 1440-1

17 Darbyshire P, Eden OB, Jameson B, et al. Pneumonitis in lymphoblastic leukaemia in childhood. European Paediatric Haematology and Oncology 1985; 2: 141-7.

18 Masur H. Prevention and treatment of pneumocystis pneumonia. N Engl f Med 1992; 327: 1853-60.

19 Haron E, Field R, Tuffnell P, et al. Hepatic candidiasis: an increasing problem in immunocompromised patients. $A m$ $\mathcal{f}$ Med 1987; 83: 17-26.

20 Levitt GA, Stiller CA, Chessells JM. Prognosis of Down's syndrome with acute leukaemia. Arch Dis Child 1990; 65: 212-6.

21 Annerén G, Magnusson CG, Lilja G, Nordvall SL. Abnormal serum IgG subclass pattern in children with Abnormal serum IgG subclass pattern in children with

22 Ragab AH, Abdel-Mageed A, Shuster JJ, et al. Clinical characteristics and treatment outcome of children with acute acteristics and treatment outcome of children with acute lymphoblastic leuka

23 Neglia JP, Meadows AT, Robinson LL, et al. Second neoplasms after acute lymphoblastic leukaemia in childhood. N Engl f Med 1991; 325: 1330-6.

24 Hawkins MM, Draper GJ, Kingston JE. Incidence of second primary tumours among childhood cancer survivors. $B r \mathcal{F}$ Cancer 1987; 56: 339-47. 